for type III achalasia and found no difference in Eckardt score and in timed barium swallow study, higher LES IRP with LHM (but still within the normal range of $<15 \mathrm{~mm} \mathrm{Hg}$ ), and a higher incidence of an abnormal pH study with POEM, as defined by a DeMeester score $>14.72$ (61\% with POEM vs $24 \%$ with LHM). However, the comparison lacked scientific strength, as no adjustments were made to account for the differences between the 2 groups.

Sudarshan and colleagues have shown that in experienced hands, POEM is a safe and highly successful treatment for the symptoms of type III achalasia, but their data also exposes reflux as a major side effect of this treatment. The higher incidence of reflux after POEM compared with LHM for achalasia was also found in a randomized trial reported by Werner and colleagues. ${ }^{2}$ This is somewhat expected, as reflux is often addressed by fundoplication during LHM. Unfortunately, the incidence and impact of longterm sequalae of this reflux (eg, severe esophagitis, Barrett's epithelium with dysplasia, stricture formation, development of malignancy, long-term effects of proton pump inhibitor use) are not yet known, as both studies had short followup times, of 1 year and 2 years, respectively.

Initial data would suggest that POEM has the highest success rate for the treatment of type III achalasia, but before deeming POEM superior, long-term implications of the resulting reflux must be established. Admittedly, owing to the rarity of this disease and patient/physician bias, a randomized study with long-term follow-up comparing POEM and LHM would be difficult, but it will be necessary to determine the ideal management for type III achalasia.

\section{References}

1. Sudarshan M, Raja S, Adhikari S, Murthy S, Thota P, Gabbard S, et al. Peroral endoscopic myotomy provides effective palliation in type III achalasia. $J$ Thorac Cardiovasc Surg. 2022;163:512-9.e1.

2. Werner YB, Hakanson B, Martinek J, Repici A, von Rahden BHA, Bredenoord AJ, et al. Endoscopic or surgical myotomy in patients with idiopathic achalasia. $N$ Engl J Med. 2019;381:2219-29.

\title{
Commentary: Peroral endoscopic myotomy, the poetic remedy for type III achalasia
}

\begin{abstract}
Abbas E. Abbas, MD
Achalasia, or lack of relaxation, was offhandedly coined by Cooper Perry for his friend Arthur Hertz, who first used the name in 1914. ${ }^{1}$ Incidentally, that same year, Ernst Heller published his report on esophagocardiomyotomy for "cardiospasm." Ironically, despite being among the most recognized ailments of the foregut, achalasia remains a disease with no identifiable etiology or cure. Pathologically, there
\end{abstract}

\footnotetext{
From the Division of Thoracic Surgery, Department of Thoracic Medicine and Surgery, Temple University Hospital and Fox Chase Comprehensive Cancer Center, Philadelphia, $\mathrm{Pa}$.

Disclosures: The author reported no conflicts of interest.

The Journal policy requires editors and reviewers to disclose conflicts of interest and to decline handling or reviewing manuscripts for which they may have a conflict of interest. The editors and reviewers of this article have no conflicts of interest.

Received for publication March 10, 2021; revisions received March 10, 2021; accepted for publication March 10, 2021; available ahead of print March 15, 2021.

Address for reprints: Abbas E. Abbas, MD, Department of Thoracic Medicine and Surgery, Lewis Katz School of Medicine, Temple University, 3401 N Broad St, Suite C-501, Philadelphia, PA 19140 (E-mail: abbas.abbas@temple.edu).

J Thorac Cardiovasc Surg 2022;163:522-3

0022-5223/\$36.00

Copyright (c) 2021 by The American Association for Thoracic Surgery

https://doi.org/10.1016/j.jtcvs.2021.03.038
}

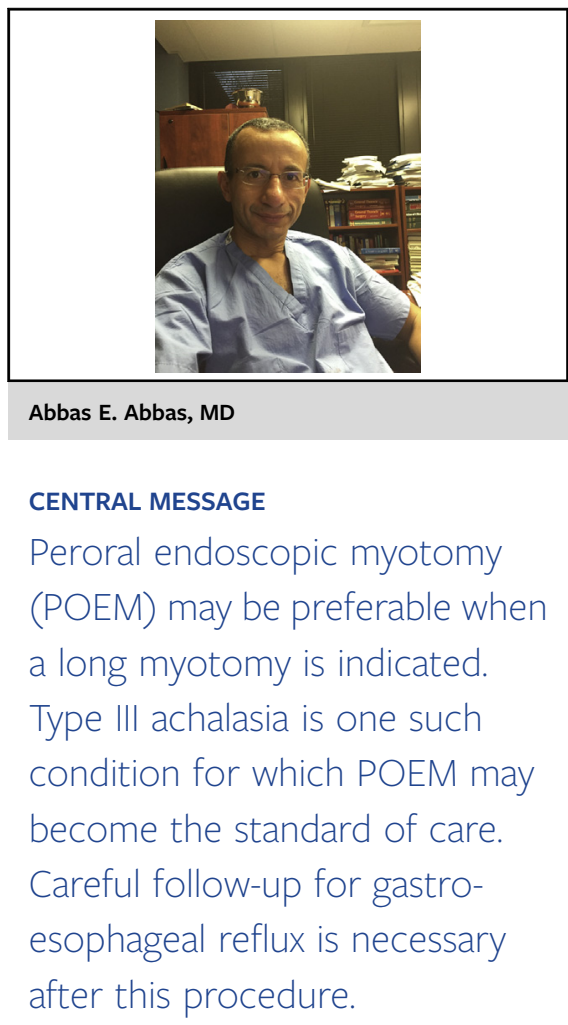


is a selective loss of inhibitory neurons in the myenteric (Auerbach) plexus, resulting in impaired relaxation of the lower esophageal sphincter (LES) and absent peristalsis. Little is known of the pathogenesis, apart from some evidence that it may be multifactorial with possible genetic predisposition and/or viral triggers causing autoimmune inflammation and fibrosis of the myenteric plexus. ${ }^{3}$

On the other hand, the pathophysiology is better understood thanks to extensive research culminating in highresolution esophageal manometry (HRM) and esophageal pressure topography (EPT). ${ }^{4} \mathrm{HRM}$ with EPT, once the stuff of high-level research, became routinely available. Building on this, an "HRM working group" was formed and developed the Chicago classification of esophageal motility disorders, first published in 2007 and now in its fourth iteration. ${ }^{5}$ Based on this classification, achalasia is classified into 3 distinct types, all with absent peristalsis and high integrated resting pressure (IRP). These subtypes have distinctive characteristics in presentation, pathology, and response to treatment.

In 2008, Inoue and colleagues ${ }^{6}$ introduced the concept of natural orifice transluminal endoscopic surgery for achalasia, dubbed peroral endoscopic myotomy (POEM), and in 2010 they published their first series. Since then, POEM has become widely adopted, with thousands of procedures performed worldwide. Numerous studies, whether case series, ${ }^{7}$ multicenter prospective, $^{8}$ or randomized, ${ }^{9}$ suggest that POEM is safe, effective, and comparable to Heller cardiomyotomy (HCM). One advantage of POEM is the ability to adjust the proximal extent of the myotomy. The impact of tailoring the myotomy length in some types of dysmotility has been theorized but not extensively studied. ${ }^{10}$ Type III achalasia, characterized by premature or spastic contractions proximal to the LES, is one condition in which a longer myotomy may be beneficial. Kane and colleagues ${ }^{11}$ reported using HRM to tailor the length of POEM in 11 patients compared with 29 nontailored patients. Postoperative Eckardt score was significantly better in the tailored group only for type III achalasia. ${ }^{11}$ Kumbhari and colleagues ${ }^{12}$ reported a retrospective study of type III achalasia comparing 49 POEM procedures to $26 \mathrm{HCM}$ procedures in which both clinical success $(98.0 \%$ vs $80.8 \% ; P=.01)$ and adverse events $(6 \%$ vs $27 \% ; P<.01)$ were significantly better in the POEM cohort. ${ }^{12}$

One of the largest exclusive studies of the rare type III achalasia is the recent study reported by Sudarshan and colleagues, ${ }^{13}$ who described their experience from 2006 to 2019 with 36 POEM and 35 HCM procedures with a median follow-up of 1 year. ${ }^{13}$ Postoperatively, the POEM group had significantly lower Eckardt scores ( 0 vs $7 ; P<.01)$, median IRP (4.5 mm Hg vs $25.5 \mathrm{~mm} \mathrm{Hg} ; P<.01$ ), 1-minute barium column height $(0 \mathrm{~cm}$ vs $10 \mathrm{~cm} ; P<.01)$, and 1 -minute barium column width $(0 \mathrm{~cm}$ vs $2 \mathrm{~cm} ; P<.01)$. Complications included 1 case each of mucosal perforation with conservative management, bleeding duodenal ulcer, and persistent dysphagia with dehydration. Postoperative esophageal $\mathrm{pH}$ studies were conducted in 21 patients $(62 \%)$, demonstrating a Demeester score of $>14.72$ in 13 patients $(62 \%)$. IRP was significantly higher at 1 year in the HCM group compared with the POEM group (7.3 vs 4.3). The HCM group also had nonsignificantly higher Eckardt scores and barium column height at 1 year.

It is clear that achalasia remains an incurable disease. Indeed, ever since 1674, when Thomas Willis reported using a sponge-tipped whalebone to push food into the stomach of a man with dysphagia, ${ }^{14}$ the basic concept of management has remained the same. Whether by forcible dilation or by surgical division of the circular muscle fibers, the only known treatment of achalasia is to disrupt the LES rather than to reverse the dysmotility and aperistalsis. The latest arrow in our antiachalasia quiver, POEM, may have benefits over its more invasive cousin, HCM, especially for long myotomies. Indeed, other than concern about unchecked gastroesophageal reflux, this procedure's elegance, simplicity, and impact are nothing short of "poetic."

\section{References}

1. Hertz AF. Achalasia of the cardia. QJM Int J Med. 1915;os-8:300-8.

2. Heller E. Extramukose kerkioplastic beim chronischen Kardiospasmus mit Dilatation desesphagus. Mitt Grenzgeb Med Chir. 1914;27:141-9.

3. Patel DA, Lappas BM, Vaezi MF. An overview of achalasia and its subtypes. Gastroenterol Hepatol (N Y). 2017;13:411-21.

4. Pandolfino JE, Roman S. High-resolution manometry: an atlas of esophageal motility disorders and findings of GERD using esophageal pressure topography. Thorac Surg Clin. 2011;21:465-75.

5. Yadlapati R, Kahrilas PJ, Fox MR, Bredenoord AJ, Gyawali CP, Roman S, et al. Esophageal motility disorders on high-resolution manometry: Chicago classification version 4.0. Neurogastroenterol Motil. 2021;33:e14058

6. Inoue H, Minami H, Kobayashi Y, Sato Y, Kaga M, Suzuki M, et al. Peroral endoscopic myotomy (POEM) for esophageal achalasia. Endoscopy. 2010;42: 265-71.

7. Petrov RV, Fajardo RA, Bakhos CT, Abbas AE. Peroral endoscopic myotomy: techniques and outcomes. Shanghai Chest. January 17, 2020 [Epub ahead of print].

8. Von Renteln D, Fuchs KH, Fockens P, Bauerfeind P, Vassiliou MC, Werner YB, et al. Peroral endoscopic myotomy for the treatment of achalasia: an international prospective multicenter study. Gastroenterology. 2013;145:309-11. e1-3.

9. Werner YB, Hakanson B, Martinek J, Repici A, von Rahden BHA, Bredenoord AJ, et al. Endoscopic or surgical myotomy in patients with idiopathic achalasia. $N$ Engl J Med. 2019;381:2219-29.

10. Fajardo RA, Petrov RV, Bakhos CT, Abbas AE. Endoscopic and surgical treatments for achalasia: who to treat and how? Gastroenterol Clin North Am 2020;49:481-98

11. Kane ED, Budhraja V, Desilets DJ, Romanelli JR. Myotomy length informed by high-resolution esophageal manometry (HREM) results in improved per-ora endoscopic myotomy (POEM) outcomes for type III achalasia. Surg Endosc. 2019;33:886-94

12. Kumbhari V, Tieu AH, Onimaru M, El Zein MH, Teitelbaum EN, Ujiki MB, et al Peroral endoscopic myotomy (POEM) vs laparoscopic Heller myotomy (LHM) for the treatment of Type III achalasia in 75 patients: a multicenter comparative study. Endosc Int Open. 2015;3:E195-201.

13. Sudarshan M, Raja1 S, Adhikari S, Murthy S, Thota P, Gabbard S, et al. Peroral endoscopic myotomy provides effective palliation in type III achalasia. J Thorac Cardiovasc Surg. 2022;163:512-9.e1.

14. Vantrappen G, Hellemans J. Motility disturbances of the esophagus. Achalasia In: Vantrappen GR, Hellemans JJ, eds. Diseases of the Esophagus. BerlinHeidelberg: Springer-Verlag; 1974:287-354. 